\title{
Supply chain risk management of organic rice in Thailand
}

\author{
Paveerat Pakdeenarong $^{\mathrm{a}^{*}}$ and Thammanoon Hengsadeekul ${ }^{\mathrm{a}}$
}

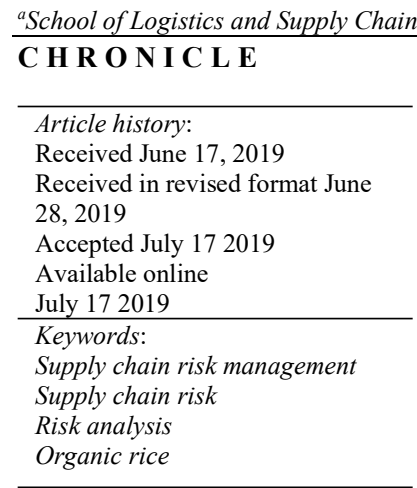

\begin{abstract}
A B S T R A C T
This study aims to identify and mitigate supply chain risks associated with organic rice in Thailand, based on the principle of supply chain risk management (SCRM). The risk measurement is performed using Best-Worst method (BWM) for ranking the criticality of different factors in order to find the appropriate ways for improving and developing new ideas for supply risk chain management. The study identifies 26 risk factors associated with the organic rice supply chain based on the literature and interviews with four experts. The order of risk priority in the organic rice supply chain in descending order (the top 5) is as follows: Lack of efficient equipment or machinery, Lack of organic rice mill, Lack of labor, Transportation cost, and Production cost. The SCRM guidelines of organic rice in Thailand include cost reduction and investment in infrastructure.
\end{abstract}

(C) 2020 by the authors; licensee Growing Science, Canada.

\section{Introduction}

The trend of a healthy and natural environment is growing in popularity. Consumers and manufactures all over the world have become increasingly aware of health and food safety, and are conscious about preserving the environment. In effect, organic goods are getting increased attention and consumers' demand for organic products is rising both domestically as well as internationally. One such preferred commodity is organic rice, which is certified by an independent body that sets the standards for organic farming. Rice is a major economic crop; Thailand's geographic location and farming policy enhances its potential for producing organic rice, which is primarily undertaken by smallholders, farmers' groups, or large agro-enterprises. Unfortunately, organic rice farming generates a lower output compared with regular rice farming. However, Thailand has a huge potential for organic production. There are several risks in the supply chain. Agricultural products have specific characteristics, such as seasonality and perishability, that make risk management for agricultural supply chain more complex. An agricultural supply chain encompasses all components of a process which includes various stages related to sourcing, producing, post-harvesting, storing, processing, and delivering. Therefore, it is important to study the supply chain risk management (SCRM) of organic rice in Thailand in order to manage and mitigate risk properly, effectively and sustainably. 


\section{Review of Literature}

\subsection{Supply Chain Risk}

Globalization has hugely impacted industrial manufacturing thereby increasing the pressure to improve quality, flexibility, and efficiency while maintaining costs. Due to this, supply chain risk is cited as the most important reason for under performance. There are many definitions of risk. Risk in general is described as uncertainty, negative, unpredictable, and an uncontrollable outcome (Aqlan \& Lam, 2016;

The Committee of Sponsoring Organizations of the Treadway Commission, 2004). From a supply chain perspective, risk is associated with the negative consequences of uncertainty within the supply chain or network (Christopher \& Lee, 2004; Wagner \& Bode, 2006). Another classification provided by Tang (2006) linked supply chain risk to the uncertainty of occurrence of an event that could affect one (or more) partner(s) or link within the supply chain and that could negatively influence the achievement of the company's business objectives and identified risks in material (source, make, deliver), information, and financial flows. Tang and Musa (2011) suggested that supply chain risks should refer to (i) events with a lower probability but could occur unexpectedly and (ii) events that bring substantial negative consequences to the system. In the agriculture supply chain; problems, risks and vulnerabilities have been discussed in various contexts such as yield, cost, and price variability for different agricultural products (Behzadi et al., 2018). Similarly, Schmitt and Snyder (2012) classified them into five forms: disruptions, lead time uncertainty, yield uncertainty, capacity uncertainty, and input cost parameter uncertainty. Yeboah et al. (2014) divided them into eight parts: (1) Weather/ Natural Disasters Risk (2) Biological and Environmental Risk (3) Market Risk (4) Logistical and Infrastructure Risk (5) Political Risk (6) Policy and Institutional Risk (7) Financial Risk (8) Operational and Managerial Risks. Tang and Tomlin (2008) explained that risk mitigation strategies are implemented in order to reduce the likelihood of occurrence and/or negative impact of risks. Hence, risk is an inherent part of the supply chain.

\subsection{Supply Chain Management}

There are various definitions of supply chain management (SCM). Mentzer et al. (2004) define supply chain as a network of suppliers who provide raw materials, parts, components, assemblies, subassemblies, and final products together with processes and customers. Typically, a supply chain process consists of manufacturing raw products and materials at factories, transporting to warehouses for storage, and delivering to customers. Chopra and Meindl (2007) explained that SCM includes different approaches and effectively integrates suppliers, manufacturers, distributors, and customers to enhance the long-term performance of individual companies and the whole supply chain in a comprehensive, high performance business model. Cao and Zhang (2011) found that SCM involves the design and management of all procurement and activities as well as the coordination and collaboration with existing network partners. In other words, SCM is the management of the flow of goods and services and includes all processes that transform raw materials into final products. Thus, SCM has become more important in the industrial world which supply and deliver products to the final customers.

\subsection{Supply Chain Risk Management}

Supply chain risk management (SCRM) is becoming an important and widely-researched subject and has many definitions. Wieland and Wallenburg (2012) define SCRM as the implementation of strategies to manage risks along the supply chain based on continuous risk assessment with the objective of reducing vulnerability and ensuring continuity. Manuj and Mentzer (2008) define SCRM as the identification and evaluation of risks and subsequent losses in the supply chain, and implementation of appropriate strategies through a coordinated approach by the supply chain members. Tang and Musa (2011) emphasize that supply chain risk is managed through coordination or collaboration among the supply chain partners to ensure profitability and continuity. In other words, SCRM is the process of applying risk management tools, together with partners in a supply chain, to address risks and uncertainties caused by, or affecting, logistics related activities or resources in the 
supply chain (Brindley, 2004). Wieland and Wallenburg (2012) showed that SCRM attempts to reduce supply chain vulnerability via a coordinated holistic approach, involving all supply chain members, which identify and analyze the risk of failure points within the supply chain. This definition was given by the Supply Chain Council research team (SCC) in 2008. SCRM is aimed at managing risks of four processes: identification, assessment, controlling, and monitoring of supply chain risks (Wieland and Wallenburg, 2011). Giannakis and Papadopoulos (2016) proposed a risk management process to identify and manage sustainability related risks demonstrated its application through empirical case studies and a survey questionnaire. Consequently, most of the manufacturers show an increasing concern about their supply chain management.

\section{Method}

\subsection{The ORSC Risks}

This section discusses the ORSC risks that may occur. There are many risks exist in each phase of ORSC. Hence, in this study, the interview was used to identify the risk factors of ORSC. After an interview with the decision team, the main risk factors were extracted and were shown in Table 1. This study was executed in Thailand. The decision team includes four expert of organic rice industry.

\section{Table 1}

\begin{tabular}{lll}
\begin{tabular}{l} 
List of ORSC Risks \\
\hline No.
\end{tabular} & Risk factors & Risk sub factors \\
\hline 1. & Source risks & $\begin{array}{l}\text { Cost of materials (S1), Lack of raw materials (S2), Unsuitable cultivated area (S3), } \\
\text { Damage or loss quality (S4), Few suppliers (S5) }\end{array}$ \\
2. & $\begin{array}{l}\text { Make } \\
\text { (Production) risks }\end{array}$ & $\begin{array}{l}\text { Production cost (MP1), Damage during production (MP2), Lack of labor (MP3), } \\
\text { Water storage (MP4), Lack of efficient equipment or machinery (MP5), Natural } \\
\text { disasters (MP6) }\end{array}$ \\
3. & Make (Mill) risks & $\begin{array}{l}\text { Process cost (MM1), Damage during process (MM2), Lack of organic rice mill } \\
\text { (MM3), Low capacity utilization (MM4), Low quality of rice milling machine } \\
\text { (MM5) }\end{array}$ \\
4. & Deliver risks & $\begin{array}{l}\text { Transportation cost (D1), Damage during delivery (D2), Transportation failure } \\
\text { (D3), Infrastructure failure (D4), Incompatible transportation procedure (D5) } \\
\text { Cost of inventory (ST1), Damage during storage (ST2), Lack of storage (ST3), } \\
\text { Inappropriate storage method (ST4), Improper packaging (ST5) }\end{array}$ \\
\hline 5
\end{tabular}

\subsection{Best Worst method (BWM)}

BMW is a comparison-oriented MCDM method that compares the best criterion to other criteria and all the other criteria to the worst criterion. The goal is to find the optimal weights and consistency ratio through a simple linear optimization model constructed by the comparison system (Rezaei et al., 2016; Ghaffari et al., 2017).

Below is a description of the steps of BWM to calculate the weight of the criteria (Rezaei et al., 2016)

1) Determine the set of decision criteria $\left\{c_{1}, c_{2}, \ldots, c_{n}\right\}$ by decision-makers.

2) Determine the best and the worst criteria to be used for the decision environment: In this step, decision-makers choose the best and the worst criteria among the set of criteria identified in Step 1 from their perspective. The best criterion represents the most important criterion and the worst criterion is the least important criterion for the decision.

3) Determine the preference of the best criterion compared with all the other criteria: A number between 1 and 9 (1: equally important, 9: extremely more important) is used to indicate this value. The resulting Best-to-Others vector would be as $\mathrm{A}_{\mathrm{B}}=\left(a_{B 1}, a_{B 2}, \ldots, a_{B n}\right)$. Where $a_{B j}$ indicates the preference of criteria $\mathrm{B}$ (best criteria) over criteria $\mathrm{j}$ and $a_{B B}=1$ 
4) Determine the preference of each of the other criteria over the worst criteria: A number between 1 and 9 is assigned to this case as well. The Others-to-Worst vector would be as $\mathrm{A}_{\mathrm{W}}=\left(a_{1 W}, a_{2 W}, \ldots\right.$ ,$\left.a_{n W}\right)^{\mathrm{T}}$, where, $a_{j W}$ indicates the preference of the criterion $j$ over the worst criteria $W$ and $a_{W w}=1$

5) Find the optimal weights $\left(w_{1}^{*}, w_{2}^{*}, \ldots, w_{n}^{*}\right)$ : Solve problem (1) to receive the optimal weights for the criteria. To determine the optimal weights of the criteria, the maximum absolute differences $\left\{\mid w_{B}-\right.$ $\left.a_{B j} w_{j}|,| w_{j}-a_{j w} w_{w} \mid\right\}$ for all $j$ should be minimized.

This model can be solved by transferring it to the linear programming (2) (Rezaei, 2015) as follows,

$$
\begin{aligned}
& \min _{\max _{j}}\left\{\left|\frac{w_{B}}{w_{j}}-a_{B j}\right|,\left|\frac{w_{j}}{w_{w}}-a_{j w}\right|\right\} \\
& \text { subject to } \\
& \sum_{j}^{n} w_{j}=1 \\
& w_{j} \geq 0, \text { for all } j \\
& \text { or } \\
& \text { min } \xi \\
& \text { subject to } \\
& \left|w_{B}-a_{B j} w_{j}\right| \leq \xi, \text { for all } \mathrm{j} \\
& \left|w_{j}-a_{j w} w_{w}\right| \leq \xi, \text { for all } \mathrm{j} \\
& \sum_{j} w_{j}=1 \\
& w_{j} \geq 0, \text { for all } j
\end{aligned}
$$

By solving this problem, the optimal weights $\left(w_{1}^{*}, w_{2}^{*}, \ldots, w_{n}^{*}\right)$ and the optimal value of $\xi^{*}$ are obtained. $\xi^{*}$ Is defined as the consistency ratio of the comparison system. It means that the closer $\xi^{*}$ is to zero the more consistent the comparison system is provided by the decision maker. Eq. (3) can be used to check the consistency of the comparisons (Rezaei et al., 2017).

$$
\text { Consistency Ratio } \quad=\quad \frac{\xi^{*}}{\text { Consistency index }}
$$

Table 2

Consistency index (CI) table

\begin{tabular}{cccccccccc}
\hline$a_{B W}$ & 1 & 2 & 3 & 4 & 5 & 6 & 7 & 8 & 9 \\
\hline Consistency index & 0.00 & 0.44 & 1.00 & 1.63 & 2.30 & 3.00 & 3.73 & 4.47 & 5.23 \\
\hline
\end{tabular}

Table 2 shows the maximum values of $\xi$ (consistency index) for different values of $a_{B W}$.

\section{Results}

At this step, BMW which was explained earlier is utilized to obtain the importance weights of ORSC Risks. 


\subsection{Determination of the Criteria Set}

The criteria set is determined on the basis of the extensive literature review and interview with experts as shown in the Table 1

\subsection{Determination of the Best and the Worst Criteria}

The second step in the BWM is the determination of the best and the worst criteria. The best criterion is the one selected by each respondent as the most important ORSC risks, while the worst criterion is the one which is the least important ORSC risks based on the opinion of each expert. Experts of this research selected Lack of efficient equipment or machinery (MP5) as the best criterion and Damage or loss quality (S4) as the worst criterion, respectively.

\subsection{Determination of the preference of the Best Criterion over all the Others}

This step consists of identifying the preferences of the best criterion from over all the other criteria. These data are gained by using BWM special questionnaire. The experts are asked to compare their selected best criterion with each of the other criteria and state their preference by using a value between 1 and 9. A score of 1 implies an equal importance over the other criteria. A score of 9 implies that the most important criterion is extremely more preferred with respect to the other criteria. Then, by calculating arithmetic mean of the four expert's questionnaires, an average weight is determined.

\subsection{Determination of the Preference of all Criteria over the Worst Criterion}

This step is similar to the previous step, but in this step, the experts are asked to state their preferences of all other criteria over the least important criterion. Similar to the previous step, a value between 1 and 9 is used. Then, by calculating Arithmetic mean of 4 expert's questionnaires, an average weight is determined.

\subsection{Determination of the ORSC Risks Weights}

The weights of ORSC Risks are calculated with a linear model (2) of BWM. By solving this linear model, optimized values of ORSC Risks weights and $\xi^{*}$ can be obtained.

\section{Table 3}

Best-to-others $(\mathrm{BO})$ and others-to-worst $(\mathrm{OW})$ pairwise comparison vectors for ORSC Risks

\begin{tabular}{|c|c|c|c|c|c|}
\hline $\mathrm{BO}$ & Source & Make (Production) & Make (Mill) & Deliver & Storage \\
\hline Best criterion: Make & 7 & 1 & 2 & 3 & 5 \\
\hline $\mathrm{OW}$ & & & & & Worst criterion: Source \\
\hline Source & & & & & 1 \\
\hline Make (Production) & & & & & 7 \\
\hline Make (Mill) & & & & & 6 \\
\hline Deliver & & & & & 5 \\
\hline Storage & & & & & 3 \\
\hline
\end{tabular}

\section{Table 4}

ORSC Risks Weight

\begin{tabular}{ccc}
\hline Criteria & Weight & Rank \\
\hline Source & 0.050 & 5 \\
Make (Production) & 0.427 & 1 \\
Make (Mill) & 0.253 & 2 \\
Deliver & 0.169 & 3 \\
Storage & 0.101 & 4 \\
$\xi^{*}$ & 0.079 & 0.035 \\
\hline Consistency Ratio & \\
\hline
\end{tabular}


170

Value of CR is closer to 0 , so in general the decision made is consistent.

Table 5

Best-to-others (BO) and others-to-worst (OW) pairwise comparison vectors for Source Risks

\begin{tabular}{lccccc}
\hline BO & S1 & S2 & S3 & S4 & S5 \\
\hline Best criterion: S1 & 1 & 3 & 2 & 7 & Worst criterion: S4 \\
\hline OW & & & & 7 \\
S1 & & & 3 & 3 \\
S2 & & & 1 \\
S3 & & & 2 \\
S4 & & & \\
\hline
\end{tabular}

Table 6

Source risks weight

\begin{tabular}{ccc}
\hline Criteria & Weight & Rank \\
\hline S1 & 0.436 & 1 \\
S2 & 0.154 & 2 \\
S3 & 0.205 & 5 \\
S4 5 & 0.060 & 4 \\
\hline$\xi^{*}$ & 0.145 & \\
\hline Consistency Ratio & 0.026 & \\
\hline
\end{tabular}

The value of $\mathrm{CR}$ is close to 0 , so in general decision made is consistent. Cost of materials (S1) received the highest ranking compared with other risk factors.

\section{Table 7}

Best-to-others (BO) and others-to-worst (OW) pairwise comparison vectors for Make (Production) Risks

\begin{tabular}{|c|c|c|c|c|c|c|}
\hline $\mathrm{BO}$ & MP1 & MP2 & MP3 & MP4 & MP5 & MP6 \\
\hline Best criterion: MP5 & 2 & 8 & 2 & 3 & 1 & 4 \\
\hline $\mathrm{OW}$ & & & & & & Worst criterion: MP2 \\
\hline MP1 & & & & & & 3 \\
\hline MP2 & & & & & & 1 \\
\hline MP3 & & & & & & 4 \\
\hline MP4 & & & & & & 4 \\
\hline MP5 & & & & & & 8 \\
\hline MP6 & & & & & & 3 \\
\hline
\end{tabular}

\section{Table 8}

Make (Production) risks weight

\begin{tabular}{ccc}
\hline Criteria & Weight & Rank \\
\hline MP1 & 0.163 & 3 \\
MP2 & 0.042 & 6 \\
MP3 & 0.199 & 2 \\
MP4 & 0.133 & 4 \\
MP5 & 0.363 & 1 \\
MP6 & 0.100 & 5 \\
\hline$\xi^{*}$ & 0.036 & \\
\hline Consistency Ratio & 0.012 & \\
\hline
\end{tabular}


Value of CR is close to 0 , so in general decision made is consistent in decision making. Lack of efficient equipment or machinery (MP5) scored the highest ranking than other Make (Production) risks.

\section{Table 9}

Best-to-others (BO) and others-to-worst (OW) pairwise comparison vectors for Make (Mill) Risks

\begin{tabular}{lccccc}
\hline BO & MM1 & MM2 & MM3 & MM4 & MM5 \\
\hline Best criterion: MM3 & 3 & 7 & 1 & 4 & 4 \\
\hline OW & & & & Worst criterion: MM2 \\
\hline MM1 & & & 4 \\
MM2 & & & 1 \\
MM3 & & & 7 \\
MM4 & & & 3 \\
MM5 & & & 3 \\
\hline
\end{tabular}

\section{Table 10}

Make (mill) risks weight

\begin{tabular}{ccc}
\hline Criteria & Weight & Rank \\
\hline MM1 & 0.189 & 2 \\
MM2 & 0.061 & 5 \\
MM3 & 0.500 & 1 \\
MM4 & 0.113 & 3 \\
\hline MM5 & 0.141 & \\
\hline$\xi^{*}$ & 0.070 & \\
\hline Consistency Ratio & 0.030 & \\
\hline
\end{tabular}

The value of CR is close to 0 , so in general decision made is consistent. Lack of organic rice mill (MM3) received the highest ranking compared other Make (Mill) risk factors.

\section{Table 11}

Best-to-others (BO) and others-to-worst (OW) pairwise comparison vectors for Deliver Risks

\begin{tabular}{|c|c|c|c|c|c|}
\hline $\mathrm{BO}$ & D1 & D2 & D3 & D4 & D5 \\
\hline Best criterion: D1 & 1 & 4 & 8 & 4 & 4 \\
\hline $\mathrm{OW}$ & & & & & Worst criterion: D3 \\
\hline D1 & & & & & 8 \\
\hline D2 & & & & & 4 \\
\hline D3 & & & & & 1 \\
\hline D4 & & & & & 3 \\
\hline D5 & & & & & 3 \\
\hline
\end{tabular}

Table 12

Deliver risks weight

\begin{tabular}{ccc}
\hline Criteria & Weight & Rank \\
\hline D1 & 0.438 & 1 \\
D2 & 0.236 & 2 \\
D3 & 0.051 & 3 \\
D4 & 0.157 & 4 \\
\hline D5 & 0.118 & \\
\hline$\xi^{*}$ & 0.034 & \\
\hline Consistency Ratio & 0.015 & \\
\hline
\end{tabular}

The value of CR is close to 0 , so in general the decision made is consistent. Transportation cost (D1) scored the highest ranking than other Deliver risk factors. 


\section{Table 13}

Best-to-others (BO) and others-to-worst (OW) pairwise comparison vectors for Storage Risks

\begin{tabular}{|c|c|c|c|c|c|}
\hline $\mathrm{BO}$ & ST1 & ST2 & ST3 & ST4 & ST5 \\
\hline Best criterion: ST1 & 1 & 2 & 3 & 7 & 5 \\
\hline $\mathrm{OW}$ & & & & & Worst criterion: ST4 \\
\hline ST1 & & & & & 7 \\
\hline ST2 & & & & & 5 \\
\hline ST3 & & & & & 4 \\
\hline ST4 & & & & & 1 \\
\hline ST5 & & & & & 2 \\
\hline
\end{tabular}

Table 14

Storage risks weight

\begin{tabular}{ccc}
\hline Criteria & Weight & Rank \\
\hline ST1 & 0.437 & 1 \\
ST2 & 0.246 & 2 \\
ST3 & 0.164 & 5 \\
ST4 & 0.055 & 4 \\
\hline ST5 & 0.098 & \\
\hline$\xi^{*}$ & 0.054 & \\
\hline Consistency Ratio & 0.024 & \\
\hline
\end{tabular}

The value of CR is close to 0 , so in general the decision made is consistent. Cost of inventory (ST1) received the highest ranking than other Storage risks.

Table 15

Supply chain risks of organic rice in Thailand

\begin{tabular}{|c|c|c|c|c|c|}
\hline Criteria & Weight & Sub-Criteria & Local Weight & Global Weight & Rank \\
\hline \multirow[t]{5}{*}{ Source } & \multirow[t]{5}{*}{0.050} & $\mathrm{~S} 1$ & 0.436 & 0.022 & 15 \\
\hline & & S2 & 0.154 & 0.008 & 22 \\
\hline & & S3 & 0.205 & 0.010 & 20 \\
\hline & & $\mathrm{S} 4$ & 0.060 & 0.003 & 25 \\
\hline & & S5 & 0.145 & 0.007 & 23 \\
\hline \multirow{6}{*}{$\begin{array}{l}\text { Make } \\
\text { (Production) }\end{array}$} & \multirow[t]{6}{*}{0.427} & MP1 & 0.163 & 0.070 & 5 \\
\hline & & MP2 & 0.042 & 0.018 & 17 \\
\hline & & MP3 & 0.199 & 0.085 & 3 \\
\hline & & MP4 & 0.133 & 0.057 & 6 \\
\hline & & MP5 & 0.363 & 0.155 & 1 \\
\hline & & MP6 & 0.100 & 0.043 & 9 \\
\hline \multirow{5}{*}{ Make (Mill) } & \multirow{5}{*}{0.253} & MM1 & 0.189 & 0.048 & 7 \\
\hline & & MM2 & 0.061 & 0.015 & 19 \\
\hline & & MM3 & 0.500 & 0.127 & 2 \\
\hline & & MM4 & 0.113 & 0.029 & 12 \\
\hline & & MM5 & 0.141 & 0.036 & 11 \\
\hline \multirow[t]{5}{*}{ Deliver } & \multirow[t]{5}{*}{0.169} & D1 & 0.438 & 0.074 & 4 \\
\hline & & D2 & 0.236 & 0.040 & 10 \\
\hline & & D3 & 0.051 & 0.009 & 21 \\
\hline & & D4 & 0.157 & 0.027 & 13 \\
\hline & & D5 & 0.118 & 0.020 & 16 \\
\hline \multirow[t]{5}{*}{ Storage } & \multirow[t]{5}{*}{0.101} & ST1 & 0.437 & 0.044 & 8 \\
\hline & & ST2 & 0.246 & 0.025 & 14 \\
\hline & & ST3 & 0.164 & 0.017 & 18 \\
\hline & & ST4 & 0.055 & 0.006 & 24 \\
\hline & & ST5 & 0.098 & 0.010 & 20 \\
\hline
\end{tabular}

As can be seen from these results, in this case, Lack of efficient equipment or machinery (MP5), Lack of organic rice mill (MM3), and Lack of labor (MP3) are the most important ORSC risks and Damage or loss quality (S4), Inappropriate storage method (ST4), and Few suppliers (S5) are the least important ORSC risks, respectively. 


\subsection{Risk Mitigation}

The recommended strategies in SCRM are as follows:

Table 16

Risk mitigation

\begin{tabular}{ll}
\hline Type of Risk & \multicolumn{1}{c}{ Risk Mitigation } \\
\hline Source & - Rice seed production: seek alternative suppliers, buffer stock, self-independent on input, use farm resources \\
and local wisdom. & - Investments in infrastructure (repair and/or replace infrastructure): farm machinery and equipment, irrigation \\
(production and & and drainage systems, water and sanitation, maintenance of physical assets. \\
mill) & - Technology (alter technology for future application): new technology (improved varieties and breeds), other \\
& improved inputs, processing technology. \\
& - Management practices: crop and livestock diversification, farming systems approach, disease and pest \\
& management practices, improved farm hygiene, raw material inventories. \\
& - Financial instruments: cost savings, access informal and formal credit for risk reducing inputs and investments. \\
& - Agriculturist group: sharing resource group assembly (Resource: Man, Money, Machine, Material, Method and \\
& Information) and working in cooperation and collaboration. \\
& - Production according to organic standard regulation because this was the appropriate method for producing \\
& organic rice and reducing waste in rice milling process or milling a large amount at a given time. \\
& - Plan for water management and water storage by digging pool or well because relying on natural rain water \\
& may cause water shortages which would be insufficient for cultivation. \\
Deliver & - Large-scale transport, communication, energy infrastructure: set the transportation regulation, the frequency \\
& in transferring, choosing the effective transportation service, speed, saving cost, quality, transportation mode, \\
& route management and transportation schedule, appropriate carriage packaging to reduce loss in transportation. \\
& This transportation could cover raw material shipping and the products which are paddy and rice. \\
Storage & Investments in infrastructure: storage and handling facilities
\end{tabular}

\section{Discussion and Conclusion}

The purpose of this research was to identify and mitigate supply chain risks prevalent in organic rice in Thailand. ORSC is a system that is formed by different member for upstream to downstream, and the whole chain is a system that requires seamless integration. In the study, first, we first determined the supply chain risks, then the factors of ORSC risk were identified. Finally, with using BWM method, the factors were ranked. Identification and ranking risk factors in ORSC helped to mitigation the risks and give the way of SCRM. According to BWM results, Lack of efficient equipment or machinery was known as the important risk of the ORSC. Hence, the efficiency of farm machinery and equipment is one of the requirements that should be considered in the context of risk mitigation. Lack of organic rice mill and labor has maintained a high rank. We can conclude that the availability of input factors including labor, money, machine, and equipment can help farmers improve efficiency and productivity in operations.

Finally, in order to gain a competitive advantage and develop the appropriate risk management strategy, the farmer should try to minimize shortages, keep cost down, invest in infrastructure (farm machinery and equipment), and coordinate all aspects of the supply chain.

\section{Acknowledgements}

The authors would like to thank the anonymous referees for constructive comments on earlier version of this paper.

\section{References}

Aqlan, F., \& Lam, S. S. (2016). Supply chain optimization under risk and uncertainty: A case study for high-end server manufacturing. Computers \& Industrial Engineering, 93, 78-87.

Behzadi, G., O'Sullivan, M., Olsen, T.L., \& Zhang, A. (2018). Agribusiness supply chain risk management: A review of quantitative decision models. Omega, 79, 21-42.

Brindley, C. (2004). Supply Chain Risk. England: Ashgate Publishing Ltd. p. 80. ISBN 0754639029. 
Cao, M., \& Zhang, Q. (2011). Supply chain collaboration: Impact on collaborative advantage and firm performance. Journal of Operations Management, 29(3), 163-180.

Chopra, S., \& Meindl, P. (2007). Supply Chain Management. Strategy, planning \& operation. In Dassumma summarum des management (pp. 265-275). Gabler.

Christopher, M., \& Lee, H. (2004). Mitigating supply chain risk through improved confidence. International Journal of Physical Distribution \& Logistics Management, 34(5), 388-396.

Ghaffari, S., Arab, A., Nafari, J., \& Manteghi, M. (2017). Investigation and evaluation of key success factors in technological innovation development based on BWM. Decision Science Letters, 6(3), 295-306.

Giannakis, M., \& Papadopoulos, T. (2016). Supply chain sustainability: A risk management approach. International Journal of Production Economics, 171, 455-470.

Manuj, Ila., \& Mentzer, J. T. (2008). Global supply chain risk management strategies. International Journal of Physical Distribution \& Logistics Management, 38(3), 192-223.

Mentzer, J. T., Myers, M. B., \& Cheung, M. S. (2004). Global market segmentation for logistics services. Industrial Marketing Management, 33(1), 15-20.

Rezaei, J., Nispeling, T., Sarkis, J., \& Tavasszy, L. (2016). A supplier selection life cycle approach integrating traditional and environmental criteria using the best worst method. Journal of Cleaner Production, 135, 577-588.

Rezaei, J., Hemmes, A., \& Tavasszy, L. (2017). Multi-criteria decision-making for complex bundling configurations in surface transportation of air freight. Journal of Air Transport Management, 61, 95-105.

Rezaei, J. (2015) Best-worst multi-criteria decision-making method: Some properties and a linear model. Omega, 64, 126-130.

Schmitt, A.J., Snyder, L.V. (2012). Infinite horizon models for inventory control under yield uncertainty and disruptions. Computers and Operations Research, 39(4), 850-62.

Sponsoring Organizations of the Treadway Commission. (2004). Enterprise Risk Management: Integrated Framework. Retrieved from https://www.coso.org/Documents/COSO-ERM-ExecutiveSummary.pdf

Tang, C. S. (2006). Perspectives in supply chain risk management. International Journal of Production Economics, 5(2), 451-488.

Tang, C., \& Tomlin, B. (2008). The power of flexibility for mitigating supply chain risks. International Journal of Production Economics, 116(1), 12-27.

Tang, O., Nurmaya Musa, S. (2011). Identifying risk issues and research advancements in supply chain risk management. International Journal of Production Economics, 133(1), 25-34.

Wagner, S. M., \& Bode, C. (2006). An empirical investigation into supply chain vulnerability. Journal of Purchasing and Supply Management, 12(6), 301-312.

Wieland, A., \& Wallenburg, C.M. (2011). Supply-Chain-Management in stürmischen Zeiten. Berlin. Universitätsverlag der TU Berlin.

Wieland, A., \& Marcus Wallenburg, C. (2012). Dealing with supply chain risks: Linking risk management practices and strategies to performance. International Journal of Physical Distribution \& Logistics Management, 42(10), 887-905.

Yeboah, N. E., Feng, Y., Daniel, O. S., \& Joseph, N. B. (2014). Agricultural supply chain risk identification-a case finding from Ghana. Journal of Management and Strategy, 5(2), 31.48.

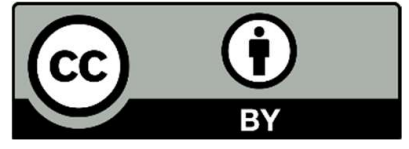

(C) 2019 by the authors; licensee Growing Science, Canada. This is an open access article distributed under the terms and conditions of the Creative Commons Attribution (CC-BY) license (http://creativecommons.org/licenses/by/4.0/). 